\title{
Evaluating Profitability Based on Integrated Method: A Case Study of Chinese Listed Airlines and Airports
}

\author{
Zhi-yuan $\mathrm{Li}^{1}$, Chong $\mathrm{Wu}^{2}$, Xin-ying Zhang ${ }^{2}$ and Yujin $\mathrm{Li}^{1}$ \\ ${ }^{1}$ School of Management, Harbin University of Science and Technology (HRBUST), Harbin, China \\ 2 School of Economics and Management, Harbin Institute of Technology, Harbin, China
}

\begin{abstract}
Due to the fact that the development of Chinese aviation industry has slowed down since the world financial crisis in 2008, how to evaluate the airline profitability improvements has become a key issue. Many mathematical methods can be applied in comprehensive evaluations, but the different focal points of these methods and the choice of methods may lead to different evaluation results, even if they are based on the same data. Both the theory and methods to evaluate the profitability of the airlines need to be developed and improved. Therefore, in order to evaluate airline management and performance, this paper presents a new approach to evaluate the Chinese aviation industry and applies towards the evaluation of 12 listed airlines and airports in the Chinese Hushen stock market. This approach overcomes the one-sidedness of a single method and obtains more comprehensive, realistic and objective results.
\end{abstract}

Keywords: profitability, Chinese listed airlines and airports, factor analysis, principal component analysis, gray evaluation

\section{Introduction}

The economic development and gradual opening of China's aviation market has grown increasingly rapidly. Chinese aviation industry continues a rapid growth, and the cost pressure is less than that in previous years. The throughput continues to maintain its high growth. For example, the growth of China's air cargo has risen by $34.5 \%$ in the past 5 years [1]; passenger throughput of Shanghai airlines will reach $100,000,000$ in 2015 [2]. Meanwhile, with the impact of the positive factors, such as the stabilization in oil prices and the appreciation of Chinese Yuan (RMB), the operating environment of the aviation industry is better than that in previous years. Therefore, an evaluation of the profitability of airlines has become the core of current research. To acquire and retain customers in such a highly profitability market, it is of strategic importance for Chinese airlines to understand the critical factors affecting their profitability and for the international aviation industry to know the operation situation of Chinese aviation market. The primary purpose of this paper is to evaluate the profitability of Chinese listed airlines according to these critical factors.

\section{Literature Review}

In the aviation industry, quite a few theoretical and empirical studies have been conducted on the evaluation of aviation profitability in terms of some key factors, such as cost [3], operational performance [4], cost and productivity, price and productivity, price and service quality [5], productivity and efficiency, probability, safety [6], service quality [7] and service quality and productivity. New theories and methods continue to make more prominent progress in the study of scientific and efficient evaluation of airlines' profitability, but there are still some points to be improved. Few researchers have studied airline profitability from a microscopic point of view, and they only focus on one certain aspect of the profitability of airlines. Therefore, these evaluations cannot truly reflect the quality of management. 
Among the dozens of contemporary comprehensive evaluation methods worldwide, there are two general categories: subjective and objective weights-based evaluation methods. The former are mostly qualitative approaches, such as Analytic Hierarchy Process (AHP) [8], and the fuzzy comprehensive evaluation method [9], where the weights are retrieved from the subjective judgments of experienced experts. The weights are determined based on the correlation between indicators or the coefficient of variation of the indicators in the latter methods, such as the Gray Relational method [10], Technique for Order Preference by Similarity to Ideal Solution (TOPSIS) [11], and Principal Component Analysis (PCA) [12]. However, when evaluating listed airlines as well as other social and economic phenomena, most scholars only use one evaluation method, such as the Factor Analysis (FA), PCA, etc [12-17].

\subsection{Analytic Hierarchy Process (AHP)}

This approach is a structured technique for dealing with complex decisions. Rather than prescribing a "correct" decision, AHP helps decision makers find the one that best suits their goal and their understanding of the problem - it is a process of organizing decisions that people are contemplating. Cheng and $\mathrm{Lu} \mathrm{[18]}$ evaluated tourism resources exploration potential of Zhangdu Lake wetland using the evaluation index system of tourism resources exploration potential. The key factors of important influence on tourism resources were analyzed and then evaluation index system of tourism resource exploration potential was established with theoretical analysis, frequency statistical method and AHP. In order to get a relatively correct index weight, their paper used the combination of AHP method and entropy technology,which, in the simple term, is the measure of the level of disorder in a closed but changing system. First, the weighs of each index were obtained through AHP method, and then they were modified by "entropy" technology. The tourism resources exploration of Zhangdu Lake Wetland Nature Reserves were evaluated and sorted based on the multi-level gray approach and evaluation index system of tourism resource exploration potential. The results showed that Mayi Lake Wetland Forest Park and Nanshan
Wetland Ecological Demonstration Area were preferential development areas with great exploration potentiality.

\subsection{Fuzzy Comprehensive Evaluation}

In enterprise profitability evaluation, the fuzziness of some factors makes them difficult to evaluate, but a comprehensive evaluation method based on fuzzy mathematics can quantitatively evaluate the profitability of enterprises to make up for the disadvantage of AHP. This method first establishes the factor sets and their weight sets, the evaluation grade sets and fuzzy evaluation matrixes, and then conducts the fuzzy comprehensive evaluation. Wang et al. [19] built a set of environmental evaluation index systems to develop the circular economy for the iron and steel industry based on the ideas and theories of circular economy. Using fuzzy comprehensive evaluation, they evaluated the steel industry in Hebei Province of circular economy development environment. Their research aims at combining characteristics of the iron and steel industry and requirements of the development of circular economy, finding support on the external environmental factors to develop the circular economy in the iron and steel industry and providing the reference in order to promote development of circular economy in the iron and steel industry.

\subsection{Gray Evaluation}

In an incomplete and inaccurate profitability system, due to many complex factors or inadequate data, multilevel gray evaluation expands the information sources and improves the reliability of evaluation and analysis. In addition, gray correlation analysis between these two factors can quantitatively analyze the correlation degree, which is more reasonable and more accurate. In the basic theory and method of the gray correlation analysis, Wang and Wang [20] used multilevel gray evaluation method to evaluate the innovation capability of hub-and-spoke enterprises clusters which combined the advantages of the analytic hierarchy process and a gray clustering method. Firstly, this paper set up a multi-hierarchy index system based on the structure and character of hub-and-spoke cluster innovation systems. Secondly, it confirmed 
the weight of every index with AHP and gave a general assessment by means of a gray clustering method. Finally, a case study was conducted to validate the evaluation model and the evaluation process. The result showed that their methodology was especially useful when there was partial information and/or qualitative variables were used.

\subsection{Technique for Order Preference by Similarity to Ideal Solution (TOPSIS)}

Ustinovichius and Simanaviciene[21] studied the sensitivity analysis for cooperative decision using TOPSIS. However, judging from the ranking decision-making steps of TOPSIS, TOPSIS has some inevitable drawbacks. (a) It is not easy to find the positive and the negative ideal solutions; (b) weight information is determined in advance, and the weight values are usually subjective, resulting in a certain subjective arbitrary; (c) in the application, due to the newly added projects, this method is prone to the reverse problems. Therefore, a more specific indepth analysis is always in need afterwards.

\subsection{Principal Component Analysis (PCA)}

PCA uses an orthogonal transformation to convert a set of observations of possibly correlated variables into a set of values of uncorrelated variables. The number of principal components is less than or equal to the number of original variables. This transformation is defined in such a way that the first principal component has as high a variance as possible, and each succeeding component in turn has the highest variance possible under the constraint, so that it can be uncorrelated with the preceding components. The PCA is mostly used as a tool in exploratory data analysis and for making predictive models [22]. However, principal components are guaranteed to be independent only if the data set is jointly normally distributed, and if the PCA is sensitive to the relative scaling of the original variables. Therefore, the application of the PCA, when there is no linear relationship among variables, may lead to the biased evaluation results. FA is an improvement over the PCA, in that it estimates how much of the variability is due to common factors. But Sternberg [23] proposes that in FA, each orientation is equally acceptable mathematically. This means that all rotations represent different underlying processes, but all rotations are equally valid outcomes of standard factor analysis optimization. Therefore, it is impossible to select the proper rotation using factor analysis alone. In addition, more than one interpretation can be made of the same data factored the same way; moreover, factor analysis cannot identify causality [24].

In summary, many mathematical methods can be applied in comprehensive evaluations, but the different focal points of these methods and the choice of methods may lead to different evaluation results, even if they are based on the same data. Both the theory and methods to evaluate the profitability of the airlines need to be developed and improved. Therefore, the core issue is to study the profitability of airlines, discuss the mechanism of airline profitability, the evaluation system and the method used to enhance profitability. In order to evaluate airline management and performance, this paper presents a new approach to evaluate the Chinese aviation industry, obtaining more comprehensive, objective, and realistic results.

\section{Basic principles}

In this paper, 12 Chinese listed airlines and airports are selected for the empirical study because the airlines and the airports are the two major operations in the Chinese aviation industry and their profitability affects each other. The relationship between airlines and airports is, customer, competitor and strategic partnership in the supply of aviation transportation. In order to evaluate and analyze the 12 Chinese listed airlines and airports comprehensively and scientifically, an integrated approach is applied. First of all, FA, PCA, and GRA are utilized to analyze and evaluate the profitability and three results are retrieved respectively. Second, KENDALL - W is used for the consistency test of these results. If they are consistent, the scores will be standardized and summed up. The final ranks will be based on the summation of the standard scores. If the results are not consistent, the three methods will be compared pair wisely. The consistent methods will be sorted together. Then, the sample data, the evaluation results, and the nature of the methods will be 
analyzed specifically, and the objective, realistic, and consistent methods will be selected for the comprehensive evaluation. The following are the detailed steps:

1. Evaluate, using FA, PCA, and GRA, respectively.

2. Test the consistency of the results by KENDALL -W.

3. Standardize the scores of each sample retrieved from each method and obtain the standard score $R_{i j}$. $\left(R_{i j}\right.$ represents the standard score of the $i^{\text {th }}$ sample in the $j^{\text {th }}$ method.)

4. Calculate $P_{i}=\sum R_{i j}$.

5. Rank according to the value of $P_{i}$.

Compared with other existing models and methods, the proposed model reflects the subjective effectiveness and the capability of the airline performances. This model has the following unique characteristics in the evaluation of airline profitability:

1. The index of this evaluation model can effectively portray the relative characteristics and trends of the dynamic changes in the airline profitability to further measure the validity of the airlines' profitability behaviors.

2. Comprehensively considering the different basic conditions of each unit, the proposed model eliminates the impacts of the objective basic conditions and truly reflects the priorities of the different economic benefits caused by the different airline profitability indicators. Therefore, it is relatively fair to use the results of the proposed model, which have strong comparability, as the indicators to measure the airline management levels.

3. The proposed model can truly reflect the contribution of the airline subjective efforts and the capability to the development of the company. This model, as a measure of the airline profitability evaluation, can motive the evaluated airlines to improve their profitability. Therefore, the airlines with good profitability conditions cannot sit back and relax, and the airlines with poor profitability will not feel it hopeless to catch up because as long as an airline makes a great progress, it will have an obvious and objective reflection in the profitability evaluation result.

\section{Empirical Study}

\subsection{Data and index}

\subsubsection{Construction Principles of the Index System}

The construction of an index system can be made in different perspectives, but it should follow some principles:

1. Systematical design. There are numerous indexes reflecting aviation profitability, so the index system has to be designed systematically;

2. Scientific feasibility. The indexes chosen not only must fully tell the aviation profitability, but also should be easily calculated;

3. Expansibility. The index system must be applicable to different countries for comparison, and should also have applicability to analyses made at different times;

4. Independence. The indexes have to be processed to be relevant to each other;

5. Objectivity. The indexes have to be objectively chosen, and the evaluation must be objectively made.

\subsubsection{Indicator analysis and selection}

Based on the above principles, the indicators in this study are selected fully and scientifically according to the financial theory, data availability, and the specific issue. These indicators can reflect the profitability of the aviation industry objectively and systematically. The five indicators for the comprehensive evaluation and analysis of the 12 Chinese listed airlines and airports are 1. Return on Sale $\left(X_{1}\right)$, 2. Cost Profit Percentage $\left(X_{2}\right), 3$. Operating margin $\left(X_{3}\right), 4$. Rate of Return on Total Assets $\left(X_{4}\right)$, and 5. Return on Equity $\left(X_{5}\right)$.

1. Return on Sale (ROS): A ratio widely used to evaluate operational efficiency of airlines. ROS is also known as "operating profit margin" of airlines. This measure is helpful to management, providing insight into how much profit is being produced per yuan of 
sales. As with many ratios, it is best to compare a ROS of an airline over time, to look for trends, and compare it to other airlines in the aviation industry. An increasing ROS indicates that the airline is growing more efficient, while a decreasing ROS could signal looming financial troubles.

2. Cost Profit Percentage: The actual margin on cost of goods is called markup. For an airline that sells service, the wholesale cost of the service sold is known as cost of service sold or the cost of sales. Margin is the difference between the sales price and the cost. Markup relates to the process of calculating the price based on its cost. Understanding these terms and how to calculate them are keys to maximizing the gross profit and net income while remaining competitive.

3. Operating margin: Also known as "operating profit margin" or "net profit margin". Operating margin is a measurement of what proportion of an airline's revenue is left over after paying variable costs such as wages, raw materials, etc. A healthy operating margin is required for an airline to be able to pay its fixed costs, such as interest on debt.

4. Rate of Return on Total Assets (ROTA): A ratio that measures an airline's earnings before interest and taxes (EBIT) against its total net assets. The ratio is considered an indicator of how effectively an airline is using its assets to generate earnings before contractual obligations must be paid. The greater an airline's earnings in proportion to its assets (and the greater the coefficient from this calculation), the more effectively that airline is said to be using its assets. To calculate ROTA, we must obtain the net income figure from an airline's income statement, and then add back interest and/or taxes that were paid during the year. The resulting number will reveal the airline's EBIT. The EBIT number should then be divided by the airline's total net assets (total assets less depreciation and any allowances for bad debts) to reveal the earnings that the airline has generated for each yuan of assets on its books.

5. Return on Equity (ROE): The amount of net income returned as a percentage of shareholders equity. Return on equity measures an airline's profitability by revealing how much profit it generates with the money shareholders have invested. The ROE is useful for comparing the profitability of an airline to that of other airlines in the aviation industry.

\subsubsection{Data sources and tools}

Original data about the above airlines come mainly from the major Chinese airline websites and various databases. Among them are multiple financial data sources, such as:

1. RESSET financial research database (retrieved from http://www.resset.cn/en/);

2. Sohu Securities (retrieved from http:// www.resset.cn/en/); and

3. financial reports of airlines.

The production data sources include:

1. Chinese transportation industry database in CSMAR. JHU's GTA-CSMAR subscriptions include the CSMAR China Stock Market Trading Database; CSMAR China Stock Market Financial Statement Research Database; and China Fund Market Research Databases for Closed-end and Open-end Funds (retrieved from http://www.gtadata.com/products/referential.aspx).

2. Civil Aviation Statistics in China Civil Aviation;

3. Civil Aviation Administration of China (CAAC); and

4. Aviation News at Eflye, a travel agency website (retrieved from http: //www . eflye.com/ index.asp). The original data have been omitted due to paper length restrictions.

SPSS14.0, MATLAB and EXCEL are the software tools for FA, PCA, and GRA.

The index system consists of both qualitative indicators and quantitative indicators, as well as both static indicators and dynamic indicators; both indicators can reflect the realistic profitability of airlines and the indicators that can predict their future profitability. This index system can help airlines identify their profitability. On different development stages, each company can change the current index system based on the actual situation in order to make more reasonable and effective evaluations. We construct 
the integrated model based on the airline profitability as shown in Figure 1.

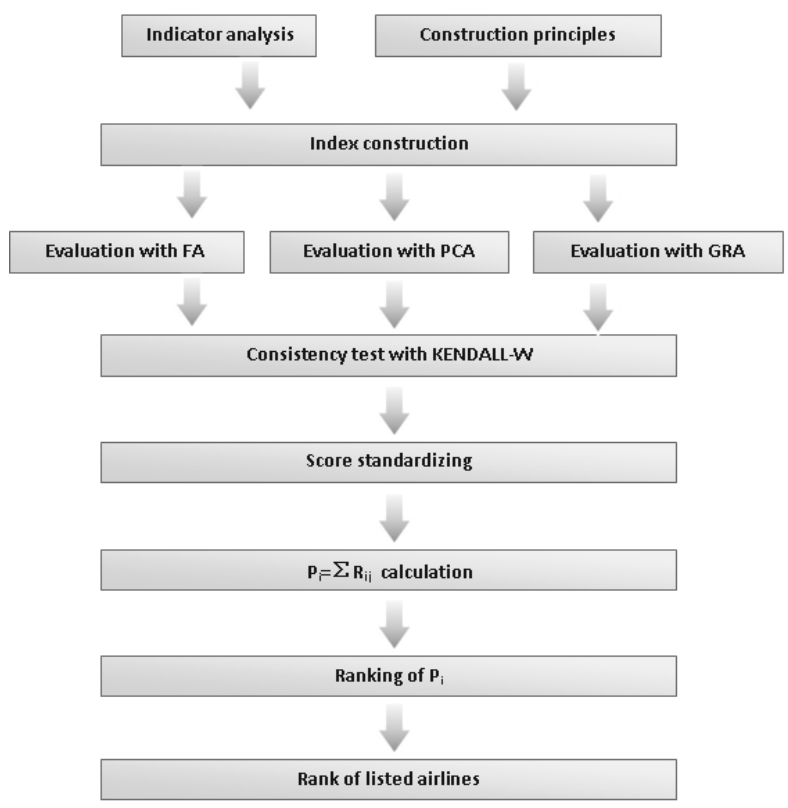

Figure 1. Empirical steps of evaluation of airline profitability.

\subsection{The comprehensive evaluation and analysis of the profitability}

\subsubsection{Factor analysis}

1. Standardize the raw data, adjust the mean of the indicators and the values of variance to
0 and 1, eliminate differences between the dimensions of variables, and obtain the following data. This step is shown in Table 1.

2. Retrieve the eigenvalue and the variance contribution rate of each factor with PCA in SPSS. According to the principle that the cumulative contribution rate should be over $85 \%, F_{1}$ and $F_{2}$ were selected as the factors whose cumulative was $89.43 \%$.

3. Obtain the factor loading matrix with the Varimax orthogonal rotation matrix, and then retrieve the scores of the factors by regression. Take the ratio of the variance contribution rate of each factor to the cumulative variance contribution rate of the remaining four factors as the weight. Aggregate the weights and retrieve $F$, which is the composite score of each company.

$$
F=\frac{F_{1} \times 0.7601+F_{2} \times 0.13425}{0.89435}
$$

\subsubsection{Principal component analysis}

1. Standardize the raw data using SPSS to establish the correlation matrix of variables $R$.

2. Calculate the eigenvalues and the corresponding contribution rates of $R$ using SPSS. The calculation results are shown in Table 2. According to the principle that the cumulative

\begin{tabular}{|l||c|c|c|c|c|}
\hline Company & $\begin{array}{c}\text { Return } \\
\text { on Sale } \\
\left(X_{1}\right)\end{array}$ & $\begin{array}{c}\text { Cost Profit } \\
\text { Percentage } \\
\left(X_{2}\right)\end{array}$ & $\begin{array}{c}\text { Operating } \\
\text { margin } \\
\left(X_{3}\right)\end{array}$ & $\begin{array}{c}\text { Rate of Return } \\
\text { on Total Assets } \\
\left(X_{4}\right)\end{array}$ & $\begin{array}{c}\text { Return } \\
\text { on Equity } \\
\left(X_{5}\right)\end{array}$ \\
\hline \hline Shanghai Airlines & -0.91 & -0.85 & -1.02 & -1.31 & -3.08 \\
\hline Hainan Airlines & -0.98 & -0.8 & -0.44 & -0.55 & 0.14 \\
\hline China Southern Airlines & -0.86 & -0.99 & -0.65 & -0.88 & -0.28 \\
\hline Shenzhen Airport & 0.65 & 1.45 & 0.56 & 0.47 & 0.4 \\
\hline Xiamen Airport & 1.51 & 1.57 & 1.37 & 1.52 & 0.51 \\
\hline Shanghai Airport & 1.23 & 0.87 & 0.45 & 0.54 & 0.42 \\
\hline Baiyun Airport & 0.63 & 1.07 & 0.57 & 0.56 & 0.43 \\
\hline COHC & 0.5 & 0.35 & 0.32 & 0.39 & 0.41 \\
\hline Hainan Airlines (B Share) & -0.98 & -0.8 & -1.08 & -0.58 & 0.14 \\
\hline Air China & -1.39 & $0-0.73$ & -1.69 & -1.62 & -0.07 \\
\hline Sinotrans & 0.83 & -0.9 & 1.59 & 1.4 & 0.49 \\
\hline Shandong Air (B Share) & -0.24 & -0.23 & 0.02 & 0.06 & 0.49 \\
\hline
\end{tabular}

Table 1. Standardized data of the profitability indicators of the listed airlines and airports. 
contribution rate should be over $85 \%$, the two factors $Y_{1}$ and $Y_{2}$ were extracted as:

$$
\begin{aligned}
Y_{1} & =0.254 \times X_{1}^{\prime}+0.208 \times X_{2}^{\prime} \\
& +0.241 \times X_{3}^{\prime}+0.255 \times X_{4}^{\prime} \\
& +0.171 \times X_{5}^{\prime},
\end{aligned}
$$

and

$$
\begin{aligned}
Y_{2} & =-0.315 \times X_{1}^{\prime}-0.364 \times X_{2}^{\prime} \\
& -0.136 \times X_{3}^{\prime}-0.04 \times X_{4}^{\prime} \\
& +1.113 \times X_{5}^{\prime},
\end{aligned}
$$

where $X_{i}^{\prime}$ was the standardized $X_{i}$.

3. Calculate $F$,

$$
F=\frac{Y_{1} \times 0.7601+Y_{2} \times 0.13425}{0.89435}
$$

\subsubsection{Gray relational analysis}

1. Establish the reference sequence based on the maximum value of each indicator. Standardize the raw data, that is, divide the maximum value of each index for each company through this index value. If the profitability of a listed company is highly correlated to this reference sequence, the score of the company will be high; that is to say, the company has high profitability.
2. Take the indicators of the 12 listed airlines as the comparison sequence. Calculate the "corresponding difference list" of each comparison and reference sequence. The maximum corresponding difference is $\Delta \max =$ 1.57 and the minimum is $\Delta \min =0$.

3. According to the actual situation of the transport industry and for simplicity, we assume that the discrimination coefficient is independent. Relaxing this assumption does not change any of the results of the model. Assume that the discrimination coefficient is $\xi=0.5$, calculate the correlation coefficient $\delta_{i}(k)$ and the correlation degree $\sigma_{i}$ of $X_{i}$, the comparison sequence and $X_{0}$, and the reference sequence, by using the formula

$$
\delta_{i}(k)=\frac{\Delta \min +\xi \Delta \max }{\Delta_{0 i}(k)+\xi \Delta \max }
$$

and

$$
\sigma_{i}=\frac{1}{N} \sum_{k=1}^{N} \delta_{i}(k),
$$

\begin{tabular}{|c|c|c|c|c|c|}
\hline Indicator & $X_{1}$ & $X_{2}$ & $X_{3}$ & $X_{4}$ & $X_{5}$ \\
\hline Reference sequence & 30.2779 & 47.3408 & 16.6442 & 12.802 & 17.48 \\
\hline Hainan Airlines & -10.51 & 4.8057 & -3.485 & -3.231 & -23.19 \\
\hline \multirow{2}{*}{ Standardization } & 1 & 1 & 1 & 1 & 1 \\
\hline & -0.34713 & 0.101513 & -0.18256 & -0.25244 & -1.32666 \\
\hline$\left|X_{0}(k)-X_{i}(k)\right|$ & 1.347 & 0.898 & 1.182 & 1.252 & 2.326 \\
\hline$\Delta_{o i}(k)$ & 134 & 487 & 56 & 437 & 659 \\
\hline$\delta_{i}(k)$ & 0.368 & 0.350 & 0.446 & 0.432 & 0.828 \\
\hline$\delta_{i}$ & & & & & 0.4852 \\
\hline
\end{tabular}

where $N$ is the number of indicators.

Specific calculation of the correlation degree is shown in Table 3. Take Hainan Airlines as an example.

4. Rank the companies based on their correlation degrees.

\begin{tabular}{|l||c|c|c|c|c|}
\hline Principal component & $Y_{1}$ & $Y_{2}$ & $Y_{3}$ & $Y_{4}$ & $Y_{5}$ \\
\hline \hline Eigenvalue & 3.8 & 0.671 & 0.478 & 0.037 & 0.014 \\
\hline Contribution rate & 0.7601 & 0.13425 & 0.09553 & 0.00733 & 0.00279 \\
\hline Cumulative contribution rate & 0.7601 & 0.89435 & 0.98988 & 0.99721 & 1 \\
\hline
\end{tabular}

Table 2. Eigenvalues and eigenvectors of the correlation coefficient matrix.

Table 3. Calculation of the correlation degree of Hainan Airlines. 


\begin{tabular}{|c|l||c|c|c|c|c|c|c|c|}
\hline \multirow{2}{*}{ No. } & \multirow{2}{*}{ Company } & \multicolumn{2}{|c||}{ PCA } & \multicolumn{2}{|c|}{ GRA } & \multicolumn{2}{|c|}{ FA } & \multirow{2}{*}{$\begin{array}{c}\text { Total } \\
\text { score }\end{array}$} & $\begin{array}{c}\text { Total } \\
\text { rank }\end{array}$ \\
\cline { 3 - 10 } & & Score & Rank & Score & Rank & Score & Rank & & \\
\hline \hline 1 & Shanghai Airlines & -1.96 & 12 & -1.38 & 12 & -0.7 & 8 & -4.04 & 12 \\
\hline 2 & Hainan Airlines & -0.49 & 8 & -0.69 & 8 & -0.84 & 9 & -2.02 & 8 \\
\hline 3 & China Southern Airlines & -0.77 & 10 & -0.91 & 10 & -0.94 & 10 & -2.62 & 10 \\
\hline 4 & Shenzhen Airport & 0.719 & 4 & 0.702 & 3 & 0.866 & 2 & 2.286 & 3 \\
\hline 5 & Xiamen Airport & 1.384 & 1 & 1.996 & 1 & 1.651 & 1 & 5.031 & 1 \\
\hline 6 & Shanghai Airport & 0.746 & 3 & 0.635 & 4 & 0.864 & 3 & 2.246 & 4 \\
\hline 7 & Baiyun Airport & 0.696 & 5 & 0.521 & 5 & 0.765 & 4 & 1.982 & 5 \\
\hline 8 & COHC & 0.463 & 6 & 0.148 & 6 & 0.392 & 6 & 1.003 & 6 \\
\hline 9 & Hainan Airlines (B Share) & -0.64 & 9 & -0.77 & 9 & -1.03 & 11 & -2.43 & 9 \\
\hline 10 & Air China & -1.18 & 11 & -1.03 & 11 & -1.53 & 12 & -3.74 & 11 \\
\hline 11 & Sinotrans & 0.912 & 2 & 0.966 & 2 & 0.71 & 5 & 2.588 & 2 \\
\hline 12 & Shandong Air (B Share) & 0.114 & 7 & -0.19 & 7 & -0.2 & 7 & -0.28 & 7 \\
\hline
\end{tabular}

Table 4. The scores and ranks in PCA, GRA, and FA.

\subsection{Evaluation scores and ranks in $P C A$, GRA, and FA}

It should be noted that the reason why the factor scores of a company were negative was that the original data were standardized, and the average of the profitability indicators was addressed as zero. Therefore, the negative profitability scores of an airline just indicated that the profitability of the company was lower than the average performance. The total score is the sum of the respective score of PCA, GRA and FA. The specific scores and ranks in the three methods are shown in Table 4.

\subsection{The test of the evaluation results with KENDALL-W}

Kendall- $W$ that can be used for assessing agreement among raters was used to examine the consistency of the evaluation results of $N$ objects from $M$ methods. Kendall- $W$ ranges from 0 (no agreement) to 1 (complete agreement) [25]:

$$
W=\frac{12 \sum_{i=1}^{n} R_{i}^{2}-3 m^{2} n(n+1)^{2}}{m^{2} n\left(n^{2}-1\right)},
$$

where $k$ denotes the number of evaluation methods, $R_{0}^{2}$ that of objects, and $R_{p}^{2}$ the sum of the rankings of these objects.

The hypothesis was that $H_{0}$ denoted the inconsistency of the rankings and $H_{1}$ the consistency.
To test if the statistic $\chi^{2}=m(n-1) W$ approximated $X_{\alpha}^{2}(n-1)$ in a large sample, determine if $X^{2} \geq X_{\alpha}^{2}$; if so, reject $H_{0}$, and accept the hypothesis of the consistency among the $m$ rankings.

According to Nonparametric tests in SPSS, the coefficient of concordance was $W=0.954$, and was approximate to the significance probability of ASYMP, with sig $=0.000<0.05$.

\section{The clustering analysis}

Take the standard scores in the three methods as the cluster indicators and cluster the 12 listed airlines with the Euclidean Distance Method. According to the clustering dendrogram generated from the SPSS 14.0 package, these airlines can be divided into three groups. The clustering results are shown in Table 5.

Two results can be generated from Table 5 . First, the clustering results of the profitability were closely related to the main business of the airlines. It was obvious that the profitability of the airports and the auxiliary companies was better than that of the transport airlines.

In Type I, Xiamen Airport was principally engaged in the service of terminal and ground facilities for domestic and international airlines. In the financial crisis, this company took efforts to promote transit operations, the implementation of the easily accessed channel, and ad 


\begin{tabular}{|c||l|c|}
\hline Type & Company & Cluster scale \\
\hline I & Xiamen Airport & 1 \\
\hline II & Baiyun Airport, Sinotrans, Shanghai Airport, COHC, Shenzhen Airport & 5 \\
\hline III & $\begin{array}{l}\text { Hainan Airlines, Hainan Airlines (B Share), China Southern Airlines, } \\
\text { Shandong Air (B Share), Air China, Shanghai Airlines }\end{array}$ & 6 \\
\hline
\end{tabular}

Table 5. Clustering Results.

hoc adherent technologies. All of these policies contributed to the development of the aviation market in Xiamen.

In Type II, the three major airports focused on transportation and the auxiliary business. Sinotrans was engaged in the import and export goods, as well as in the agency business of the transit of the international goods across the border. The main business of $\mathrm{COHC}$ was oil services.

In Type III, the airlines are all engaged in the passenger and cargo transportations. Their performance was poor in 2010 for the following reasons: (1) the global financial crisis reduced the demand; (2) Oil prices increased dramatically; (3) The tendency towards RMB appreciation slowed down; and (4), a large purchase of aircraft also increased the airline's respective financial burdens and depreciation costs.

Secondly, in the poor financial conditions the profitability of the airlines is inversely proportional to the size of the company. In Type III, small companies, namely, Hainan Airlines (B Share), Shandong Air (B Share), and Hainan Airlines were rated better than large airlines such as China Southern Airlines, Air China, and Shanghai Airlines. The reason why is believed to be the fact that the big companies could not achieve similar economies of scale as compared to the small airlines, as well as the fixed cost of the amortization.

\section{Conclusions}

From the final evaluation results, we can see that the profitability of Xiamen Airport ranked first in the aviation industry, which is consistent with the actual condition. In this paper, a comprehensive evaluation approach was proposed based on the previous evaluation methods. This paper has (1) enriched the theory of airline profitability,(2) built a more scientific and comprehensive evaluation index system of airline profitability, (3) constructed a new integrated profitability evaluation model and (4) conducted an empirical study of the improved model based on the data from 12 Chinese airlines and airports. The ranking results of the proposed method, theory and model coincide with the real conditions of the airline market. Therefore, our evaluation of airline profitability is accurate, reliable and objective.

This improvement of the model overcomes the one-sidedness of a single method and the disadvantages of other methods, and eliminates the difference of various evaluation methods. This approach leads to the more objective, comprehensive, and realistic evaluation results. In particular, the final evaluation scores can be clustered to obtain a more accurate classification. This model can offer some suggestions and reference to various evaluations of the listed companies. This way of choosing the benchmarking companies in the listed companies is also a helpful tool to study the benchmarking companies and propose the improvement policies for listed companies. The proposed method cannot only be a comprehensive analysis and evaluation of the profitability of the listed airlines, but also helps the investors to understand the status and the weak points of the listed Chinese airlines.

Based on the related literature and our own empirical study, further research and discussion may include studying (1) the profitability evaluations of Chinese and international airlines, (2) the enrichment and the improvement of the evaluation theory and methodology, (3) the selection of non-financial indicators in the profitability evaluation, and (4) the detailed recommendations and suggestions for the airlines' management. 


\section{References}

[1] LI HAIYAN, Passenger throughput of Shanghai airlines will reach $100,000,000$ in 2015. 2012, retrieved from CAAC News: http://www. caacnews.com.cn/newsshow . aspx?idnews $=193067$

[2] HAN LEI, Growth of $34.5 \%$ of China's air cargo in the past 5 years". 2011, retrieved from CAAC News: http://editor. caacnews.com.cn/mhb/html/ 2012-11/01/content_106353.htm

[3] K. Button, A. Costa, F. Costa, C. CRuz, Problems of cost recovery by European airlines since market liberalization. Transportation Planning and Technology, 34(2) (2011), 125-138.

[4] C. P. Barrosa, N. PeypochB, An evaluation of European airlines' operational performance. International Journal of Production Economics, 122(2) (2009), 525-533.

[5] Bureau OF TRANSPORT AND COMMUniCATIONS ECONOMICS, The progress of aviation reform. Canberra: Australian Government Publishing Service, 34. Rep. No. 81, 1993.

[6] C. F. Chena, S. C. ChEnA, Scale development of safety management system evaluation for the airline industry. it Accident Analysis \& Prevention, 47 (2012), 177-181.

[7] J. J. H. LiOU, C. C. HsU, W. C. YeH, R. H. LiN, Using a modified gray relation method for improving airline service quality. Tourism Management, 32(6) (2011), 1381-1388.

[8] M. T. IsaAi, A. Kanani, M. Tootoonchi, H. R. AFZALI, Intelligent timetable evaluation using fuzzy AHP. Expert Systems with Applications, 38(4) (2011), 3718-3723.

[9] L. WANG, W.-H. HU, An applied study on multifactors-level-fuzzy-overall-evaluation in profit capacity analysis of stocked corporations. Quantitative and Technical Economics, 17(1) (2000), 59-61.

[10] J. J. H. LIOU, C.-C. HsU, W.-C. YEH, R.-H. LIN, Using a modified gray relation method for improving airline service quality. Tourism Management, 32(6) (2011), 1381-1388.

[11] G. Torlak, M. Sevkli, M. Sanal, S. Zaim, Analyzing business competition by using fuzzy TOPSIS method: An example of Turkish domestic airline industry. Expert Systems with Applications, 38(4) (2011), 3396-3406.

[12] S. SiQInG, W. LI, W. Jing, H. Yi, H. FAN, Research on e-Government evaluation model based on the principal component analysis. Information Technology and Management, 12(2) (2011), 173-185.

[13] D. YUAN, Research on the model of sports industry profitability based on factor analysis and principal component analysis. JDCTA: International Journal of Digital Content Technology and its Applications, 7(2) (2013), 288-296.
[14] M. JiA, Z. DEDONG, Y. YIXIAN, Digital watermarking based on contourlet transform and principal component analysis. JDCTA, 7(4) (2013), 434-442.

[15] F. ZHANG, A new evaluation method based on dynamic incentive model and its application in operation performance evaluation of listed companies. JCIT, 7(14) (2012), 27-35.

[16] H. SHI, W. Du, L. ZHOU, Optimization model for fresh agricultural products supply chain network based on nonlinear integer programming. AISS, 5(3) (2013), 107-115.

[17] J.-S. QI, Z.-H. JIANG, C. WU, An international comparative research of the technical efficiency in China corporations - taken the China air transport corporations as an example. Studies in Science of Science, 5 (2008), 1006-1013.

[18] G.-Z. ChENG, S.-P. LU, The multilevel gray evaluation of tourism resources in the Zhangdu Lake wetland. Journal of Xiangfan Vocational and Technical College, 9(6) (2010), 48-51.

[19] J. WANG, R. ZhaO, X. WANG, Fuzzy comprehensive evaluation on Hebei steel industry environment for the development of circular economy. Ecological Economy, 10 (2011), 343-349.

[20] L. WANG, K. WANG, The multilevel gray evaluation of innovation capability of Hub-and-Spoke enterprise clusters. International Conference on Information Management, (2009), pp. 254-257.

[21] L. Ustinovichius, R. Simanaviciene, The sensitivity analysis for cooperative decision by TOPSIS method. 7th International Conference on Cooperative Design, Visualization, and Engineering, (2010), pp. 89-96.

[22] P. J. A. SHAW, Multivariate statistics for the environmental sciences. Hodder Arnold, England, 2003.

[23] R. J. STERNBERG, Intelligence, information processing, and analogical reasoning: The componential analysis of human abilities. Lawrence Erlbaum Associates, USA, 1977.

[24] R. B. Darlington, S. L. Weinberg, H. J. WalBERG, Canonical variate analysis and related techniques. Review of Educational Research, 43 (1973), 453-454.

[25] M. G. Kendall, B. B. SMith, The problem of $m$ rankings. The Annals of Mathematical Statistics, 10(3) (1939), 275-287. 
Contact addresses:

Zhi-yuan Li

School of Management

Harbin University of Science and Technology (HRBUST)

Harbin

China

e-mail: andysee2008@sohu.com

Chong Wu

School of Economics and Management Harbin Institute of Technology

Harbin

e-mail: wuchong@hit.edu.cn

Xin-ying Zhang

School of Economics and Management Harbin Institute of Technology

Harbin

e-mail: xin-ying.zhang@hotmail.com

Yu-jin Li

School of Managemen

Harbin University of Science and Technology (HRBUST)

Harbin

China
ZHI-YUAN LI is a lecturer at the School of Management, Harbin University of Science and Technology (HRBUST), Harbin, China. He, with major of Technoeconomics \& Management, is author and reviewer of several articles in scientific journals indexed by SCI, SSCI and EI and international conferences. His research interests are in the areas of technology economics and management, producer services, and high-tech industrial cluster (HIC). Zhi-yuan Li is a corresponding author.

CHONG Wu is Professor at the School of Economics and Management, Harbin Institute of Technology (HIT), Harbin, China. He is Vice President of the Department of Management Science and Engineering at the School of Economics and Management, Harbin Institute of Technology. He holds a PhD in Mathematics from the Science School, HIT and a Postdoctoral degree in Management Science and Engineering from the School of Business and Economics, HIT. He is author and reviewer of several articles in scientific journals indexed by SCI, SSCI and EI and international conferences. His research interests are in the areas of financial econometrics, quantitative finance, computational statistics, time series analysis, multivariate data analysis and forecasting.

XIN-YING ZHANG is a student at the School of Economics and Management, Harbin Institute of Technology (HIT), Harbin, China and author and reviewer of several papers in international conferences and journals indexed by SCI, SSCI and EI. She collaborated with authors from America, Spain, Britain and Taiwan in the field of management and published her translation work Train Your Brain when she studied as a joint $\mathrm{PhD}$ at the University of Utah, USA. Her current research interests are in the areas of modern financial engineering, ANN (Artificial Neural Network) in management, EPNN (Elliptical Probabilistic Neural Network), credit risk management, and management and decision analysis.

YU-JIN LI is a postgraduate student at the School of Management, Harbin University of Science and Technology (HRBUST), Harbin, China. Her research interest is in the area of logistics engineering. 